\title{
Project Management System Based on Work-Breakdown-Structure Process Model
}

\author{
Akira Harada $^{1}$, Satoshi Awane ${ }^{1}$, Yuji Inoya ${ }^{1}$, Osamu Ohno ${ }^{1}$, \\ Makoto Matsushita $^{2}$, Shinji Kusumoto ${ }^{2}$, and Katsuro Inoue ${ }^{2}$ \\ ${ }^{1}$ Engineering Support Management Division, Solution Systems, Hitachi Ltd. \\ 890 Kashimada Kawasaki, Kanagawa, 213-8567, Japan \\ \{aharada, awane, yinoya, ohno \}@itg.hitachi.co.jp \\ ${ }^{2}$ Department of Computer Science \\ Graduate School of Information Science and Technology \\ Osaka University \\ 1-3, Machikaneyama, Toyonaka, Osaka 560-8531,Japan \\ \{matusita, kusumoto, inoue\}@ist.osaka-u.ac.jp
}

\begin{abstract}
We have developed a "WBS(Work Breakdown Structure) process model" for a business application software development project. We have also developed a project management system called "PRO-NAVI" which works on the "WBS process model." This WBS process model" provides (1) mutual mapping between the "software development processes", "activities", "products", "know-how," "rules", and "standards", and provides (2) comprehensive control. The role of "project management" in a business application software development project is recognized to be of more importance. These projects generally involve huge efforts, and cost heavy payloads to their "project management." Thus, an efficient project management system is needed. We have developed "PRO-NAVI". We have applied and evaluated "PRO-NAVI" with a number of projects and confirmed that it is effective for efficient project fulfillment.
\end{abstract}

\section{INTRODUCTION}

Digitization and networking of the society is accelerated, such as seen in diffusion ofthe Internet and the World Wide Web, and in business application software development, requirements for larger scale, higher function, shorter delivery schedule, and lower cost are urged. Accordingly, role of project management is becoming more important to carry out business application software development projects as planned: [1],[2],[3],[4].

Generally in a project management, repetition of so called Plan-Do-Check-Action process, make plan, execute it, check progress situation, and take action if necessary is said to be fundamental. A project is a set of multiple works and their consequential products, and a project management is a facilitation to make these works done with efficiency and to manage works and products. Therefore, a system to support a project management is required. 
This paper is a proposal of a management method of works and products and a project management support method based on WBS(Work Breakdown Structure) process model: [5],[6],[7],[8]

We also show our actual development of "PRO-NAVI", which is a WBS-based project management system.

As project management systems, MS-Project [9], ProcessDirector [10], and KnowledgePLAN [11] are well known products. As Product document management systems, DocumentBroker [12] and documentum [13] are well known products. We thought a new point of view is required, to relate and use with efficiency, of project process information, work information, product information, know-how information, which both of above have. PRO-NAVI" provides [a] clear definition of software development process, work, and products of the project at the project planning phase, [b] grasp of project progress status, [c] standardization of software project development process and navigation, [d] sharing of project knowledge such as project products and "know-how." These improve efficiency of project promotion. PRO-NAVI" is used by more than 1,000 projects by now and will be used more.

In this paper, we will show modeling of a business application software project by WBS in chapter 2, realization of "PRO-NAVI" in chapter 3, we will also show an application example, evaluation and consideration in chapter 4 , and we will show a summary and address future issues in chapter 5.

\section{WBS}

WBS is a hierarchy chart to describe project goals in detail.

\subsection{WBS process model}

Department of Defense handbook "Work Breakdown Structure" defines WBS as below: [5]

(1) A product-oriented family tree composed of hardware, software, services, data, and facilities. The family tree results from systems engineering efforts during the acquisition of a defense material item.

(2) A WBS displays and defines the product, or products, to be developed and/or produced. It relates the elements of work to be accomplished to each other and to the end product.

(3) A WBS can be expressed down to any level of interest. However the top three levels are as far as any program or contract need go unless the items identified are high cost or high risk. Then, and only then, is it important to take the work breakdown structure to a lower level of definition.

"PMBOK" defines WBS as, "A deliverable-oriented grouping of project elements that organizes and defines the total work scope of the project. Each descending level represents an increasingly detailed definition of the project work,: [6]"

In this paper, we will explain according to the definition of [6]. We will also call each element of WBS as "work". 


\subsection{Project planning based on WBS}

\section{(1) "Standard PRO-NAVI WBS"}

We propose a five layer WBS process model for a software development project and name it "Standard PRO-NAVI WBS".

[a] first layer: project [b]second layer: sub-project [c]third layer: phase [d]fourth layer: work step [e]fifth layer: product

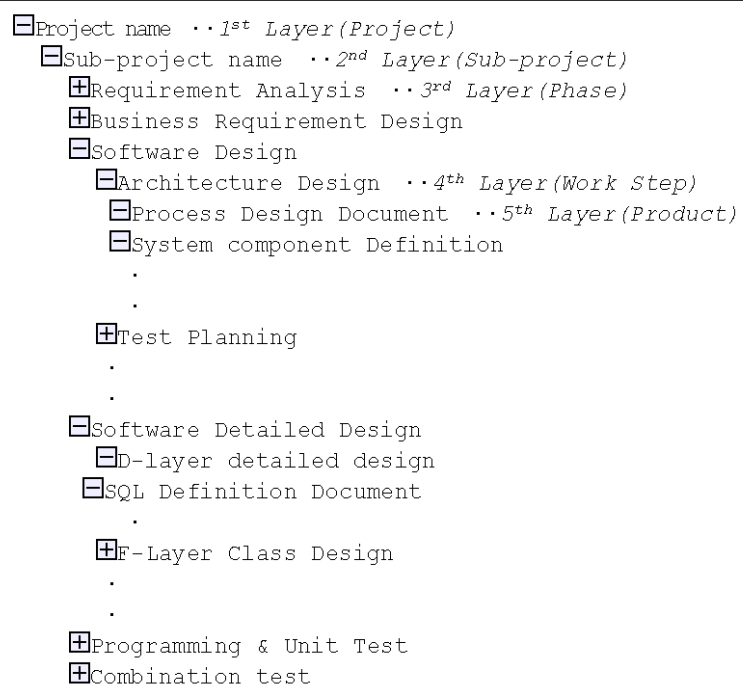

Fig.1. Standard PRO-NAVI WBS

Figure 1 shows an example of Standard PRO-NAVI WBS".

First layer is the project itself.

We divide the whole software to be developed by a project to several loosely related sub systems and name each project to develop one of these sub systems as sub-project. We define this sub-project as the second layer. For example, for a project to develop a management administration system for an enterprise, first layer will be "management administration system", second layer will be sub systems of the management administration system such as "employee management system," "account management system," "merchandise management system," and so on.

"Standard PRO-NAVI WBS" defines names of works in $3^{\text {rd }}, 4^{\text {th }}$, and $5^{\text {th }}$ layer as shown in Figure 1.

Third layer, that is, phase, is equivalent to waterfall model development phase: [14],[15], and it divides the project lifecycle into 7 phases, namely, requirement analysis, business requirement design, software design, software detailed design, programming and unit test, combination test, and integrated or system test. These phases proceed with time by the above order. 
The fourth layer, or work step, divides the work of each phase into multiple concrete works. Software design for example, will be divided into following 7 work steps: architecture design, test planning, business process design, database layer class design, function layer class design, presentation layer event design, and physical database design.

Fifth layer, or product, includes process design document, system component definition, business flow diagram, display transition diagrams and so on.

Product entities are managed by files. One product is designed to be constituted by one or more than one files so that more than one project members can share the works concerning one product. For example, process design document can be made of two following files, online process design document and batch process design document. We call this file as product file, and this product file will not show up to standard PRO-NAVI WBS. We simply call product file as product when it is not necessary to make distinction. A chronological order do exist among phases as listed, however, no peculiar relation in time exists among work steps and products. These work steps, work items correspond to activities and tasks of SLCP-JCF98, which is a common frame for software centric development and trades: [16]

A project member may need to refer to prerequisite products to do a work.

A project member may also be able to do works efficiently with common project know-how and knowledge of standards, procedures, and worksheets.So, we add two kinds of common information items to each of "Standard PRO-NAVI WBS"[17]:

1) prerequisite works prior to the current work,

2) common knowledge required, such as rules and procedures.

\section{(2) Optimization of "Standard PRO-NAVI WBS"}

A "Standard PRO-NAVI WBS" defines a standard business application software development process, and may cause excess or deficiency of works for actual projects. So, we made a concept of "customized PRO-NAVI WBS," which is a derivative of "Standard PRO-NAVI WBS", giving more details and layers, adding necessary works, deleting unnecessary works, renaming works, so as to optimize "Standard PRO-NAVI WBS" for a peculiar project. However, we have given restrictions on deletion or change of specific works in the "Standard PRO-NAVI WBS" in order to enforce a certain "common structure" to the "customized PRO-NAVI WBSs" for various projects. By this, we can easily promote standardization of project management method because the "customized PRO-NAVI WBSs" for various projects have same product names, work names, and similar basic structures. When there is no need to make distinctions between "Standard PRO-NAVI WBS" and "customized PRO-NAVI WBS", we simply call them as "PRO-NAVI WBS." We have prepared multiple, not one, Standard PRO-NAVI WBSs", so that the "customized PRO-NAVI WBSs" can be made with ease.

When deriving a "customized PRO-NAVI WBS," we also optimize prerequisite works and common information accordingly. The common information will be added common reference information of the project.

(3) A project planning based on "PRO-NAVI WBS"

A project plan can be clearly defined by deciding project start date, project finish date, project members, work start dates, work finish dates, work member assignments. 
So, we add two kinds of information items to each work of "PRO-NAVI WBS":

1) assigned members, due dates, and progress status of the work (started, not started, completed, reviewed and approved),

2) product files that constitutes an product, assigned member, updated time, version number and progress status.

By this, we can have following effects:

1) A project plan and its progress status are clear to its members, and project plan and progress information can be easily accessed, because the "PRO-NAVI WBS"structure is identical to the project's development process.

2) Project's common knowledge such as products, rules, procedures and worksheets can be easily found and referred because they are not only uniformly managed but also related to respective works, thus higher quality, higher efficiency and standardization of works can be done.

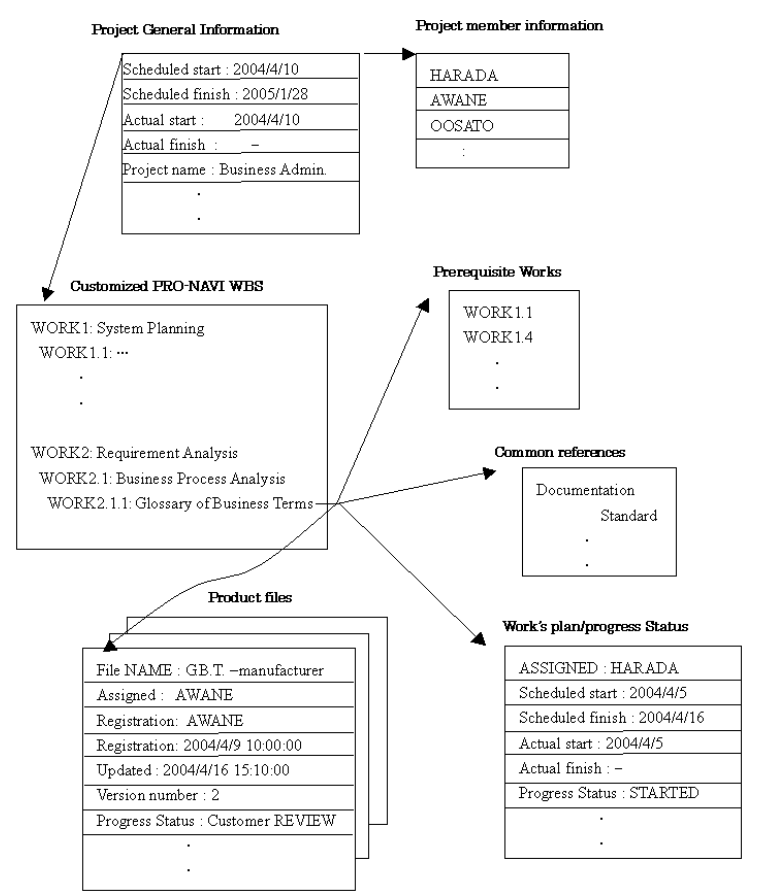

Fig.2. An example of attached information to PRO-NAVI WBS

Figure 2 shows an example of information added to the "PRO-NAVI WBS". In this example, "customized PRO-NAVI WBS" and project member information are added to project general information of a business administration project. Additionally, plan of work itself and prerequisite works, common references, and product files information are also added. Figure 2 shows one member HARADA is scheduled to finish a glossary of business terms by $2004 / 4 / 16$, and manufacturer's part of the glossary of business terms is assigned to AWANE and was updated on 2004/4/16. 


\section{3. "PRO-NAVI"}

We have developed a project management system "PRO-NAVI", based on "PRO-NAVI WBS process model." In this chapter, we explain the schematics, functions and implementation of "PRO-NAVI".

\subsection{Structure and functions of "PRO-NAVI"}

\section{(1) Structure of "PRO-NAVI"}

Figure 3 shows the structure of "PRO-NAVI".

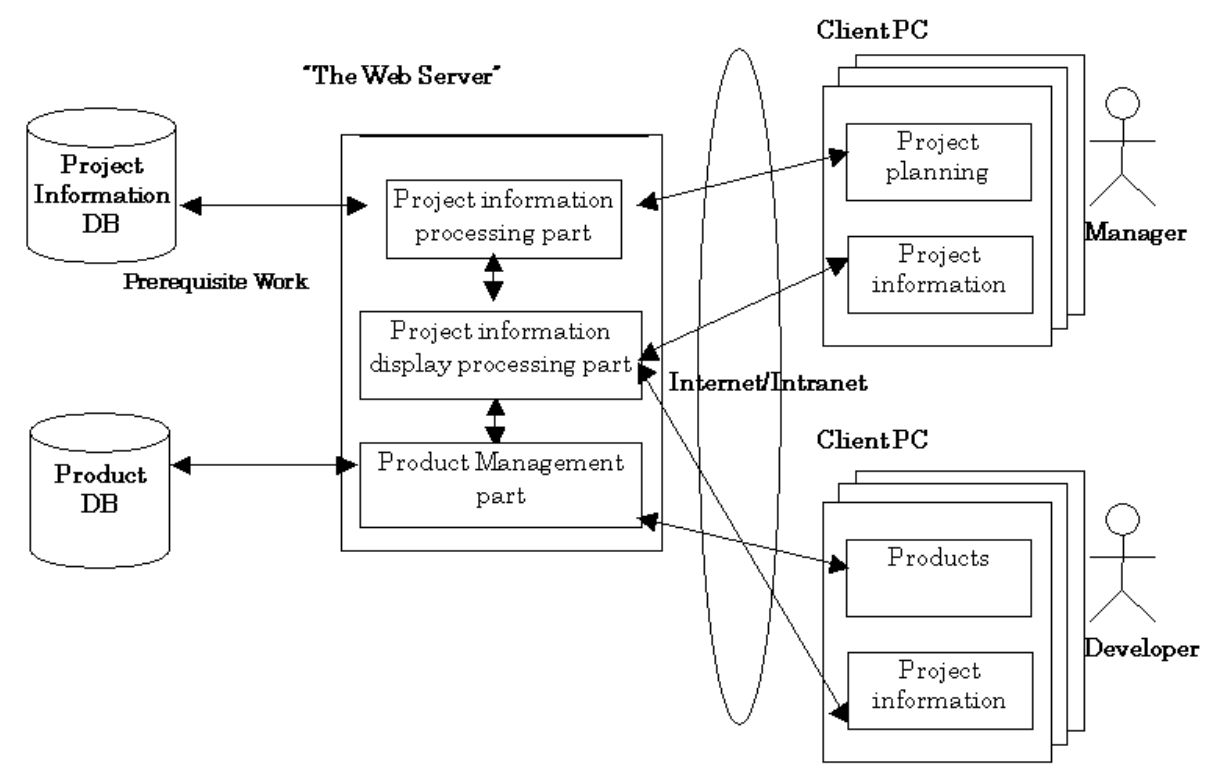

Fig.3. The structure of PRO-NAVI

"PRO-NAVI" is composed of "the Web server" and more than one client PCs, and they communicate through the Internet or intranet. The "Web server" is connected with the Project information DB and the Product DB. The Project information DB stores the information shown in Figure 2. The Product DB stores product files, which are entities of products. "The Web server" has project information processing part, project information display processing part and product management part. A project plan which is made on a manager's client PC will be sent to "the Web server", and then processed by the project information processing part, and then stored in the Project information DB. A project information which is stored in the Project information DB, 
will be processed by the project information display processing part, and then sent to the manager's client PC or to a developer's client PC, and then displayed.

\section{(2) Project information display function}

Two kinds of project information display functions for each project member's client PC are provided and are called private view and project view.

\section{(a) private view}

The private view is a screen to display the works, a list of product files, and the progress status of the project member who operates his or her client PC. Actual screen example is shown in Figure 4. This example shows multiple projects or sub projects one member participates in, works assigned, a list of product files made and registered. The "project path (in Japanese)"represents first and second layers of the "PRO-NAVI WBS", and "work path (in Japanese)" represents the third layer or below.

The first item of Figure 4 shows he or she is assigned to a "business integration project (in Japanese)", is assigned a project work "definition of non-functional requirements (system requirements) (in Japanese) ", and the due date is "2004/12/10", and the progress status is "started (in Japanese)".If one member belongs to multiple projects, all the works assigned and a list of product files of those projects will be displayed.

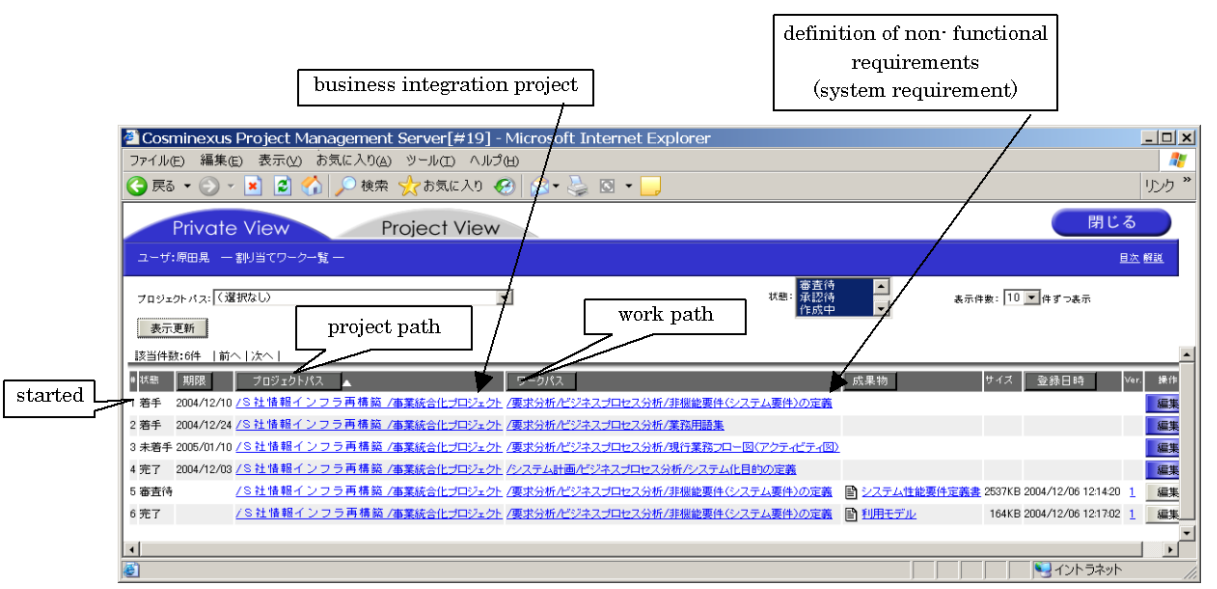

Fig.4. An example of private view

\section{(b)project view}

The project view is a screen to display "PRO-NAVI WBS," product information of each WORK, and reference information of each WORK. A screen example is shown in Figure 5. If one selects a work on "PRO-NAVI WBS display frame" on the left of the screen, related WORK and a list of product files, assigned members, due dates, and progress status will be displayed as "Product information display frame" on the upper right of the screen. If one selects a product file in addition, he or she can view a file registered as a product. 


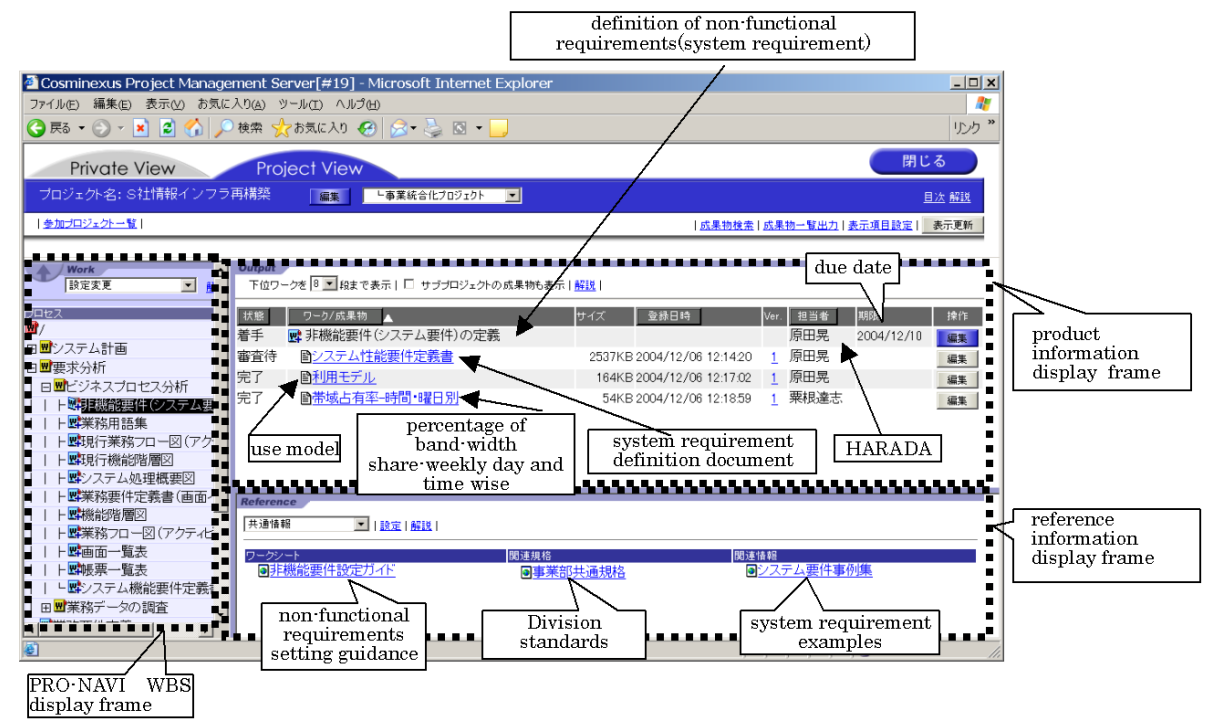

Fig.5. An example of project view

A "reference information display frame" on the lower right of the screen displays products and common information of the organization to be referenced. If one selects one item, he or she can read a relevant document. For example, in Figure 5, one has selected "definition of non-functional requirements (system requirements) (in Japanese) " of "PRO-NAVI WBS display frame", and the "Product information display frame" displays assigned member as HARADA (in Japanese), due date (in Japanese) as 2004/12/10, and status (in Japanese) as "started" are displayed. In addition, "definition of non-functional requirements (system requirements) (in Japanese)" is composed of three product files and displayed with assigned member names and status, namely, "system requirement definition document", "use model", "percentage of band-width share - weekly day and time wise."

Also, the "reference information display frame" displays common information to refer when defining non-functional requirements (system requirements), namely, "non-functional requirements setting guidance (in Japanese)", "Division standard", and "system requirement examples".

\section{(3) Other functions}

\section{(a) Managers' functions}

1) Project managers are able to make project plans based on "PRO-NAVI WBS," by putting in necessary information through his or her client PC with ease, because prototypes of WBS, prerequisite WORKs, and common information are provided by "Standard PRO-NAVI WBS." These project plans will be transmitted through the network and then stored in the "Project information DB."

2) Project managers refer to "Product information display frame" of the project view and then evaluate progress status by project planning, and status of works and product files. 
3) Project managers may directly read product files and confirm progress status or percentage of completion independent from project member's report, if necessary.

4) Project managers choose one product file from a list which is displayed in the "Product information display frame", and check the contents, review, or approve, and then reflect the result to the "status".

\section{(b) Developers' functions}

1) A developer refers to his or her client PC's private view or project view and confirms assigned works; this is called "To Do management".

2) A developer refers to his or her project view and recognizes participating project's plan and progress status.

3) A developer selects product files and downloads them to the client PC from a list displayed in his or her private view or project view, and then do assigned works, update product files.

4) If prerequisite work products or a common reference of the organization is found to be required while making an assigned product, a developer selects a necessary material from "Reference information display frame", and then downloads it to the client PC and refers to it.

5) An updated most recent product will be sent to the server and then stored in Product DB. At this time, version number of the product file will be also updated by 1 , hence version management of product files are also performed by version numbers.

6) On completion of the assigned product, a developer changes status of the product and the product files to "COMPLETED."

By 1), start priorities and due dates of the products are shown, and by 4), directions and examples of contents and formats of the products are shown, and thus these are "Navigator" of works. We name this as "NAVIGATION FUNCTION".

\section{Evaluation}

We will state the application record and effects of "PRO-NAVI."

\subsection{Actual application record of "PRO-NAVI"}

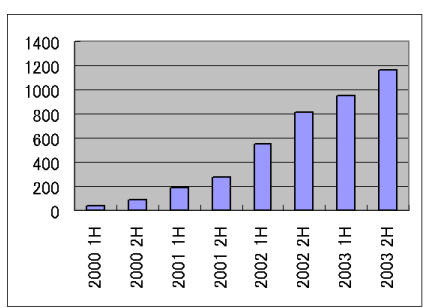

Fig.6. The cumulative number of the projects using PRO-NAVI

Figure 6 shows the cumulative number of the projects using "PRO-NAVI." We started the operation of "PRO-NAVI" on March, 2000. By March, 2004, approximately 1200 
projects are using "PRO-NAVI." The number of product files registered counts approximately 310,000 by March, 2004. We think "PRO-NAVI" has become the standard project management system of in-house use.

We have added new "standard PRO-NAVI WBSs," as the number of "PRO-NAVI" users grows. We had just two standard WBSs at the beginning. Now we can choose from 13 types of "standard PRO-NAVI WBSs" for each project and then optimize it. Added "standard PRO-NAVI WBSs" are developed with name-changes, check-process-additions and unnecessary-work-deletions corresponding to our customer's business fields and their organizations, as shown in Figure 7.

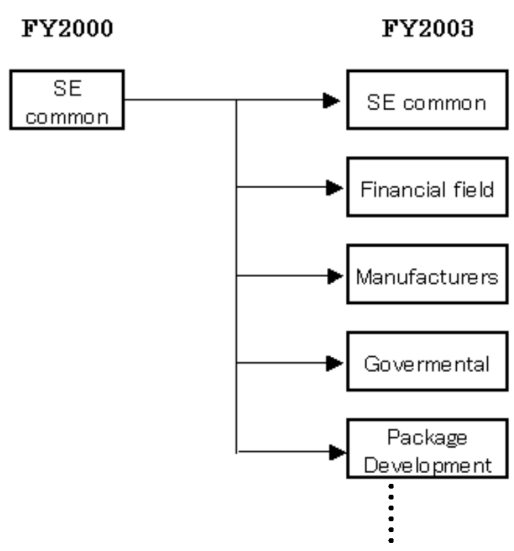

Fig.7. Types of standard PRO-NAVI WBSs

For example, for the financial field WBS, we have added detailed improvements concerning systems operation. We have added detailed works such as emergency operation manuals and tests. A project manager selects an appropriate "standard PRO-NAVI WBS", related with customer's business field and customer's role in the company, optimizes it, and then starts a project.

We have favorable evaluations from "PRO-NAVI" users, as shown below.

(1) Getting across job of the project standard document and project development plan to its project members has become easier.

(2) Development errors due to "version-mistakes" have disappeared, because most recent products can be shared in a secured manner.

(3) Search job for necessary products has become much easier.

(4) Distribution job of products has become easier.

(5) Hard copy document distribution has decreased.

(6) Version management of products has become possible.

(7) A project manager can easily verify the project status report, because the project manager can directly check the status of the product and its contents with "PRO-NAVI". 


\subsection{An application example of "PRO-NAVI"}

A railroad company ticket system construction project: 800 Kilo source lines of code to be developed, by 200 project members in 10 separate development locations. This large scale project applied "PRO-NAVI" to achieve high efficiency development and management level and to share project progress status, product files and project common documents.

(1) Optimized "standard PRO-NAVI WBS" for the project.

Figure 8 shows the optimization process of "standard PRO-NAVI WBS" to the project above.

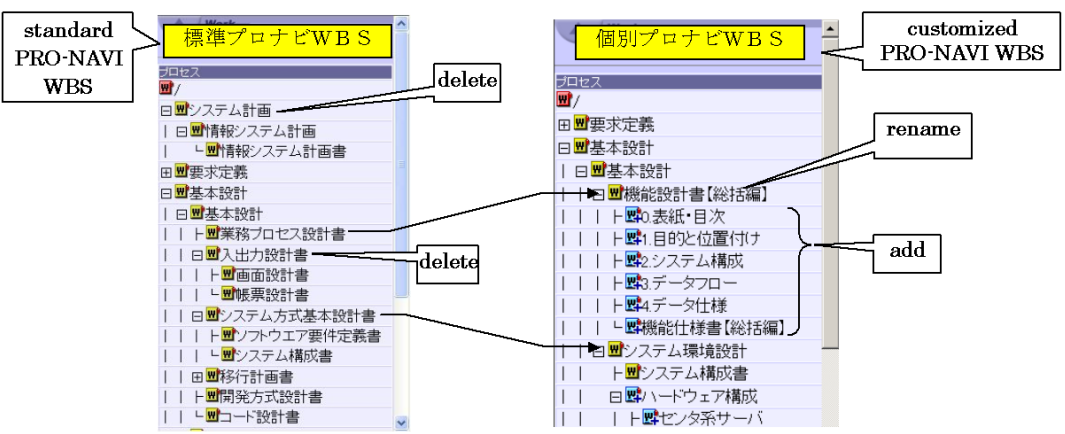

Fig.8. An example of customization of PRO-NAVI WBS

Optimization points are as follows:

(a) Unnecessary works or products are deleted. Here, (system planning) and (I/O design document) are deleted.

(b) Standard names of works are renamed to that of peculiar ones in the project. In Figure 8,

the name of (business process design document) is renamed to (function design document -comprehensive part-).

(c) Divided works are added as $6^{\text {th }}$ layer, so that a project member can be assigned to a divided product. In Figure 8, (function design document -comprehensive part-) is divided to (0. top cover/outline) and (1. Purpose and positioning).

(2) Comprehensive management of products and common documents.

The "PRO-NAVI" managed 391 product files as outcomes of design process, and 173 common documents.

\section{(3) Accurate grasp of the project progress status}

The "PRO-NAVI" "s product information display frame provides products progress status, and a manager may directly access to each product. Thus, a project manager can directly feel and confirm progress status of products and their quality. The project is to have prescheduled progress meetings, and project members are to report their progresses. The project manager compared project member's report with "PRO-NAVI confirmation result", and warned the project member, whose confirmation result was 
much different, and realized early detection of progress problems and suitable countermeasures.

\section{(4) Application result of "PRO-NAVI"}

Effects of using "PRO-NAVI" are given in Table 1.

Table 1. Effects of using PRO-NAVI

\begin{tabular}{|l|}
\hline \multicolumn{1}{|c|}{ Effects of using "PRO-NAVI" } \\
\hline $\begin{array}{l}\text { Project planning has become easier because "standard PRO-NAVI WBS" lists standard works neatly } \\
\text { and "customized PRO-NAVI WBS" can be made without fault. }\end{array}$ \\
\hline $\begin{array}{l}\text { Project management efficiency for product management and progress management, which were } \\
\text { troublesome chores due to the huge number of project members, has been improved } 20 \%\end{array}$ \\
\hline Project products can be checked with ease. \\
\hline $\begin{array}{l}\text { Specification checks have become easier and rudimentary errors have faded out, and reutilization of } \\
\text { other project member's products has become easier and project efficiency has been improved, because } \\
\text { the most recent version of the products can be easily accessed by other project members. }\end{array}$ \\
\hline $\begin{array}{l}\text { Navigation of development jobs has become possible by referring to project's shared common } \\
\text { documents such as procedures and writing examples. And it has supported efficient development. }\end{array}$ \\
\hline $\begin{array}{l}\text { Instantaneous distribution of the most recent information to project members among } 10 \text { remote } \\
\text { development sites has been realized. }\end{array}$ \\
\hline
\end{tabular}

On the other hand, product progress status gathering function is pointed out to be an issue.

For example, to grasp project progress status, one needs to select a work in "PRONAVI WBS display frame" of the project view, and then check its progress work by work in "product information display frame". This operation method has advantage in grasping percentage of completion of products, however, it costs effort to grasp project progress status, and requires a new function to sum up product progress.

\subsection{Analysis and Considerations}

From application results of "PRO-NAVI" until now, we have confirmed three effects as follows: (1) Clarification and notification of project plan throughout the project. (2) Correct grasp of project progress status. (3) Higher quality, higher efficiency, standardization of the project due to easy access to products and common documents. It is also recognized, with "PRO-NAVI", one can grasp progress status with ease, however to grasp comprehensive project progress status, one needs to select work by work from project view displays, and this costs effort. For this issue, an automatic collection apparatus of project progress status based on products is effective, and we should make research.

\section{CONCLUSIONS}

In this paper, we have proposed a WBS process model to relate project process, project works, project products, and project's common knowledge such as know-how, rules, 
and standards and a project management system "PRO-NAVI". As is shown in chapter 4, "PRO-NAVI" provides (1) Clarification of software development process, work, and products of the project at the planning phase, (2) a grasp of project progress status, (3) standardization of software project development process and navigation, (4) sharing of project knowledge such as project products and "know-how." We have confirmed the "PRO-NAVI" is an effective system to support a project management.

On the other hand, project progress status gathering is pointed out to be a bothersome and burdensome job and requires much effort. Our next step will be the research and development of an automatic collection and evaluation function of project progress status based on products which are registered in "PRO-NAVI".

\section{References}

1. H. Kerzner, Project Management, John Wiley\&Sons, Inc. New York (2001)

2. R. Rada, J. Craparo, " Standardizing software projects," Communications of the ACM, vol.43, no. 12 (Dec. 2000) 21-25

3. Watts S. Humphrey, Managing the Software Process, Addison-Wesley, Winthrop (1989)

4. Shunichi Fukuyama, Hideo Takagi, Ryoji Tanaka, Michihiro Watanabe, Isao Nakabayashi: Procedures for Implementing Checklists that Provide Guidance for Continuous Improvements in Software Processes, IPSJ Journal, vol.42, no.3 (March 2001) 529-541

5. Department of Defense handbook Work Breakdown Structure(MIL-HDBK-881), Department of Defense, USA (1998)

6. A Guide to the Project Management Body of Knowledge 2000edition, Project Management Institute, Newtown Square (2000) Glossary

7. Gregory T. Haugan, Effective Work Breakdown Structures, Management Concepts, Vienna (2002)

8. Practice Standard for Work Breakdown Structures, Project Management Institute, Newtown Square (2001)

9. Eric Uyttewaal, Dynamic scheduling with Microsoft Project2002, J. Ross Publishing and International Institute for Learning, Boca Raton (2003)

10. KABUSHIKIKAISHA NEC, KORABOREISHON-GATA PUROJEKUTOKANRI SISUTEM ProcessDirector (in JAPANESE), http://www.sw.nec.co.jp/cced/processdirector

11. KABUSHIKIKAISHA KOUZOUKEIKAKUKENKYUUJYO, SOFUTOUEA MITSUMORI TUURU KnowledgePLAN (in JAPANESE), http://www4.kke.co.jp/sec/service/o1.html

12. KABUSHIKIKAISHA HITACHI SEISAKUSHO, BUNSHOKANRIKIBAN DocumentBroker Version2 (in JAPANESE), http://www.hitachi.co.jp/Prod/comp/soft1/docbro/index.html

13. NIPPON DOKYUMENTAMU KABUSHIKIKAISHA , documentum (in JAPANESE), http://www.documentum.co.jp

14. C. Jones, Applied Software Measurement, The MeGraw-Hill Companies, New York (1996)

15. H. Kerzner, Applied Project Management, John Wiley\&Sons, Inc., New York (2000)

16. KYOUTUUFUREIMU98-SLCP-JCF98-(1998 NENBAN), SLCP-JCF98IINKAI, KABUSHIKIKAISHA TSUUSANSIRYOUTYOUSAKAI, TOKYO (1998) (in Japanese)

17. Y. Oka, T. Tanida, S. Konno, C. Hirai, "Operation assistance method and system and recording medium for storing operation assistance method," U.S. Patent no.6799183, (Sep.2004) 